\title{
ANALISIS PEMBELAJARAN IPA PADA MATERI CAHAYA DENGAN LESSON STUDY BERBASIS TBLA (TRANSCRIPT BASED LESSON ANALYSIS) KELAS VIII SMP ISLAM AL-FALAH KOTA JAMBI
}

\author{
${ }^{1)}$ Melisa Murzanita, ${ }^{1}{ }^{*}$ Nova Susanti, ${ }^{1)}$ Neneng Lestari \\ ${ }^{1)}$ Universitas Jambi, Jalan Lintas Jambi - Ma. Bulian Km 15 Mendalo Indah, Muaro Jambi 36136 \\ e-mail: nova_fisikaunja@unja.ac.id
}

\begin{abstract}
This study aims to apply lesson study and analyze the science learning process through lesson study based on TBLA (Transcript Based Lesson Analysis) where the analysis is focused on teacher centered and student centered. The stages of lesson study carried out are plan, do and see. This study uses a qualitative approach with the type of case study research in class VIII.2 SMP Islam Al-Falah Jambi City through 2 research cycles. Sources of qualitative data obtained through observation and documentation. Observations were made during the learning process while documentation was obtained from audio/video recordings of the learning process (interactions between teachers and students) which were then transcribed in the form of dialogue between teachers and students. The results obtained are based on the analysis of learning transcripts made in the form of word unit graphs, it can be seen that the science learning process in cycle 1 is dominated by the teacher, but students are also quite active in learning seen from students answering questions given by the teacher. While cycle 2 is done to improve learning in cycle 1 , namely learning is done with group discussions with the aim that students are more active. However, the learning process is still dominated by the teacher. The conclusion in this study is that science learning through lesson study on light material has been carried out well in accordance with the lesson study stages and the science learning process is still dominated by the teacher
\end{abstract}

Key word: Science Learning, Transcript Based Lesson Analysis, Lesson Study

\section{PENDAHULUAN}

Pendidikan merupakan suatu hal yang sangat penting karena pendidikan dapat dijadikan tolak ukur atau pandangan suatu bangsa atau negara. Namun saat ini pendidikan di Indonesia belum sepenuhnya terlaksana dengan baik. Salah satu permasalahan pendidikan yang masih menjadi prioritas adalah kualitas pendidikan yang khususnya kualitas pembelajaran. Peningkatan mutu pendidikan tidak hanya dapat ditingkatkan melalui perbaikan kurikulum atau sistem pendidikan. Peningkatan mutu pendidikan harus diikuti dengan kemampuan dan kesiapan pendidik, kesiapan kepala sekolah, dan kesiapan fasilitas sekolah.
Guru merupakan penunjang utama bagi mutu dan kualitas pendidikan. Sebagai orang yang terdepan guru harus memiliki kemampuan dan kesiapan yang matang untuk memberikan ilmu serta membimbing dan mendidik peserta didik. (Dewi, 2018) mengatakan, sebagai inisiator guru harus mencetuskan ide-ide kemajuan dalam pendidikan dan pengajaran. Sebab, untuk meningkatkan kualitas pendidikan di negara kita, salah satunya dimulai dengan memperbaiki proses edukasi yang ada supaya sesuai dengan perkembangan ilmu pengetahuan dan teknologi. Dengan demikian, guru pun harus meningkatkan kemampuannya dibidang pendidikan dan pengajaran, 
antara lain dengan meningkatkan kemampuan menggunakan media dan strategi pembelajaran yang sesuai dengan perkembangan saat ini.

Dalam proses pendidikan hasil belajar yang baik merupakan suatu hal yang diinginkan setiap peserta didik. Hal tersebut tidak lepas dari kemampuan seorang guru dalam mendesain pembelajaran yang merupakan faktor penentu keberhasilan dalam belajar. Menurut (Ernawati \& Effendi, 2017) Perencanaan pembelajaran dilakukan dengan memperhatikan beberapa unsur yaitu tujuan pembelajaran, isi atau materi pembelajaran, metode pembelajaran, dan media pembelajaran, unsur-unsur pembelajaran tersebut merupakan satu kesatuan yang tidak dapat dipisahkan.

Fisika merupakan salah satu cabang Sains yang menjadi dasar perkembangan ilmu pengetahuan dan teknologi. Mata pelajaran fisika sangat erat kaitannya dengan fenomena-fenomena alam dan aplikasinya dalam kehidupan sehari-hari sehingga siswa dituntut untuk memahami konsep dari pelajaran yang diberikan. Tetapi mata pelajaran fisika kurang diminati oleh banyak siswa karena fisika dianggap sulit dan susah untuk dipahami. Menurut (Sari et al,. 2019), siswa masih mengalami kebingungan dalam menjelaskan sebuah konsep, selain itu pemahaman konsep siswa juga masih kurang. Sedangkan (Kusdiastuti et al., 2019) mengatakan bahwa, kenyataan dilapangan pembelajaran fisika dalam prosesnya cenderung bersifat satu arah. Artinya, guru aktif menyampaikan materi dan peserta didik hanya mendengarkan penyampaian materi dari guru biasa disebut dengan Teacher centered. Padahal peserta didik harus berperan aktif dan bekerja sama satu sama lain untuk mengembangkan kemampuan berfikirnya (Student Centered)

Menurut (Ernawati \& Effendi, 2017) Salah satu faktor yang mempengaruhi keberhasilan guru dalam melaksanakan pembelajaran fisika adalah ketepatan dalam memilih serta menerapkan pembelajaran yang sesuai dengan materi pembelajaran. Lesson study merupakan salah satu pembelajaran yang tepat diterapkan dalam pembelajaran fisika atau IPA. Salah satu faktanya yaitu berdasarkan penelitian yang dilakukan oleh (Maison et al., 2015) diperoleh bahwa kegiatan lesson study yang telah dilakukan di SMP 17 Kota Jambi bisa meningkatkan kualitas proses pembelajaran. Kegiatan ini juga mampu meningkatkan aktivitas siswa dan guru dalam proses pembelajaran yang ditandai dengan adanya akibat-akibat yang sudah dapat dilihat pada pembelajaran IPA khususnya Fisika di kelas yang dijadikan target binaan lesson study.

Lesson study merupakan suatu pembelajaran yang dilaksanakan oleh guru secara kolaboratif dan berkelanjutan. Dalam pelaksanaannya menurut Slamet Mulyana (2007) dalam (Suminem, 2016), lesson study meliputi tiga bagian kegiatan, yaitu perencanaan (plan), implementasi (do) dan refleksi (see). Tujuan utama lesson study yaitu memperbaiki kualitas pembelajaran peserta didik, proses pembelajaran haruslah terpusat pada siswa bukan guru.

Analisis terhadap proses pembelajaran perlu dilakukan agar guru nantinya dapat memperbaiki kualitas pembelajaran. Analisis yang dilakukan yaitu berupa analisis proses pembelajaran apakah bersifat teacher centered atau student centered melalui lesson study. Menurut (Setyosari, 2020) Guru dalam melakukan analisis pembelajaran perlu mempertimbangkan faktor-faktor yang berkenaan dengan siswa, lingkungan belajar, dan tujuan yang ingin dicapai. Romagnano, dkk (2008) dalam (Rahayu et al., 2020) Analisis pembelajaran adalah cara untuk melihat, mendengar, mendeskripsikan, mendiskusikan, dan memahami interaksi antara guru dan siswa selama pembelajaran. Untuk mencapai hal tersebut maka perlu dilakukan suatu analisis secara lebih mendalam yaitu melalui observasi, perekaman, membuat 
transkrip serta menganalisisnya. Salah satu metode analisis untuk mentranskrip pembelajaran yang dapat digunakan dalam kegiatan lesson study yaitu TBLA (Transcript Based Lesson Analysis).

TBLA merupakan salah satu teknik dari lesson study yang digunakan untuk menganalisis situasi dalam proses pembelajaran. Di dalam model TBLA guru mengamati dan mentranskripsikan praktik mengajar mereka sendiri, menganalisis dan merefleksikannya, serta mendiskusikannya secara kolaboratif dengan guru lain. Dengan melakukan ini, guru dapat meningkatkan kemampuan mereka untuk mereview naskah pengajaran serta kemampuan pengambilan keputusan dan modal profesional mereka secara terus menerus (Sarkar Arani, 2017).

\section{METODE}

Penelitian ini menggunakan pendekatan kualitatif dengan jenis penelitian yaitu studi kasus. Studi kasus merupakan strategi penelitian dimana didalamnya peneliti menyelidiki secara cermat suatu program, peristiwa, aktivitas, proses, atau sekelompok individu. Kasuskasus dibatasi oleh waktu dan aktivitas, dan peneliti mengumpulkan informasi secara lengkap dengan menggunakan berbagai prosedur pengumpulan data berdasarkan waktu yang telah ditentukan ((Stake, 1995) dalam (Creswell, 2017)). Peneletian ini dilaksanakan di SMP Islam Al-Falah Kota jambi dengan waktu pelaksanaan semester genap tahun 2020/2021.

Dalam penelitian ini akan dilakukan pengumpulan data kualitatif dengan sumber data yaitu siswa kelas VIII.2 yang berjumlah 32 orang dengan rincian 20 siswa laki-laki dan 12 siswa perempuan. Data kualitatif diperoleh melalui observasi dan dokumentasi. Observasi dilakukan oleh pengamat pada saat proses pembelajaran berlangsung yang selanjutnya observasi tersebut dijadikan acuan ataupun di bahas pada saat refleksi dengan tujuan untuk memperbaiki pembelajaran selanjutnya, sementara dokumentasi diperoleh dari rekaman audio/video proses pembelajaran (interaksi antara guru dan siswa) yang kemudian akan di transkrip dalam bentuk dialog pembelajaran.

Penelitian ini dilaksanakan dalam beberapa siklus kegiatan lesson study yang terdiri dari siklus I dan II. Tetapi jika belum mendapatkan hasil yang diinginkan kegiatan dapat ditambah sampai mendapatkan hasil yang diinginkan. Namun jika telah mendapatkan hasil yang diinginkan sebelum kegiatan II dapat dihentikan sampai kegiatan II saja. Dalam penelitian ini peneliti sebagai guru model akan berkolaborasi dengan dosen pembimbing, guru bidang studi IPA yang mengajar di SMP Islam Al-Falah Kota Jambi beserta tim observer. Skema kegiatan lesson study yang dilaksanakan yaitu seperti pada gambar 1:

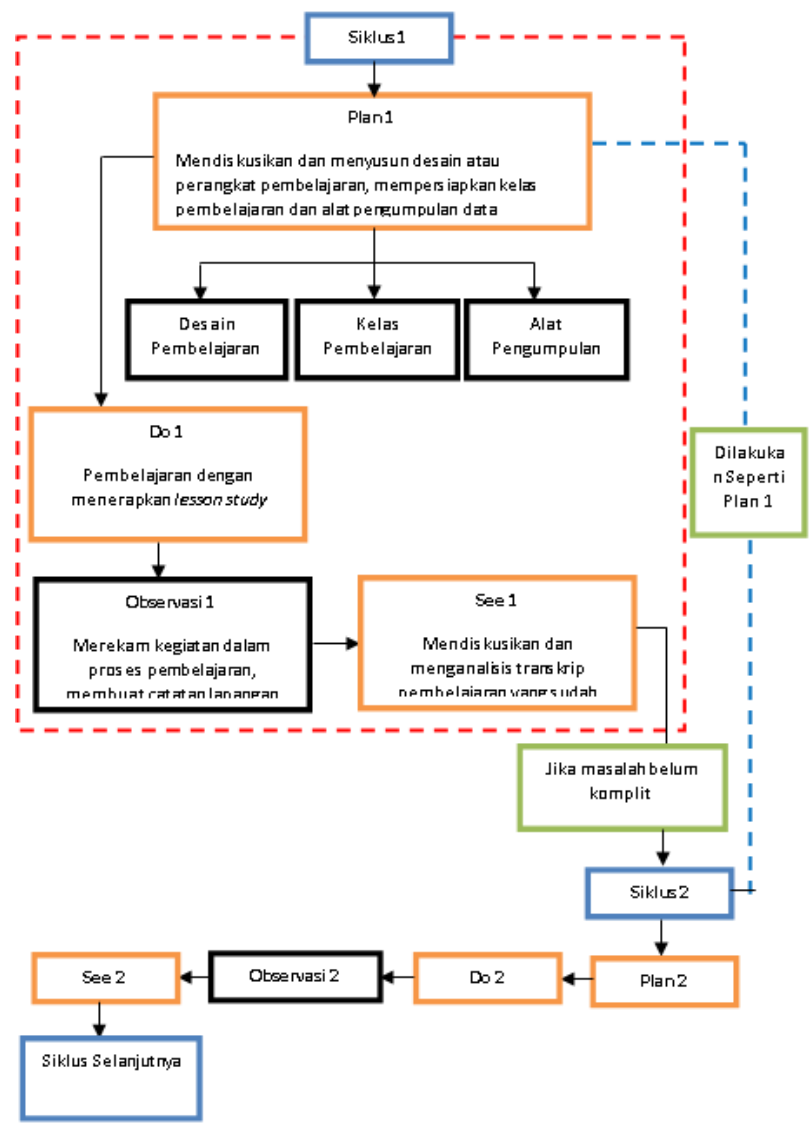

Gambar 1. Skema kegiatan lesson study Sumber: Susanti, dkk (2016) 
Biasanya proses belajar mengajar dilakukan di kelas, namun pandemi covid19 saat ini mengharuskan proses belajar mengajar dialihkan menjadi daring atau virtual. Disekolah tersebut proses belajar mengajar dilaksanakan melalui aplikasi Google meet dimana guru bidang studi akan membagikan link pembelajaran kepada guru model dan siswa, oleh karena itu durasi pembelajaran dibatasi hanya 30 menit saja. Karena banyak pertimbangan dan kelemahan dari pembelajaran daring ini diantaranya harus memiliki jaringan yang kuat untuk bergabung dan memakan banyak biaya bagi penggunanya.

\section{a. Perencanaan (plan)}

Pada tahap perencanaan (plan) siklus 1 peneliti menyiapkan perangkat pembelajaran seperti desain pembelajaran, media pembelajaran, kelas pembelajaran, observer yang berjumlah 12 orang dimana setiap observer akan mengamati satu siswa yang telah ditentukan oleh peneliti dan alat perekam audio/video yang digunakan pada saat pembelajaran berlangsung yang kemudian di diskusikan dengan melibatkan dosen, guru IPA dan para observer. Pada tahap ini dosen dan guru IPA menyarankan kepada peneliti sebagai guru model untuk melakukan praktik mengajar sebelum mengajar dikelas yang telah ditentukan, hal ini bertujuan untuk melihat apakah tujuan pembelajaran yang telah dibuat bisa tercapai dalam waktu yang telah ditentukan. tahap plan pada siklus I berjalan dengan baik sebagai mana mesti nya.

Pada siklus 2 peneliti juga menyiapkan perangkat pembelajaran seperti siklus 1. Tetapi pada siklus 2 ini peneliti sebagai guru model tidak melakukan praktik mengajar, karena dosen dan IPA menyarankan agar pelaksanaan pembelajaran pada siklus 2 dilaksanakan dengan diskusi kelompok bagi siswa. Peneliti membagi siswa dalam 4 kelompok dengan satu kelompok berjumlah 8 orang.

b. Pelaksanaan (do)

Pada tahap pelaksanaan (do) siklus 1 dan 2 peneliti sebagai guru model melaksanakan pembelajaan melalui aplikasi google meet. Observer yang bergabung dapat mengamati bagaimana proses pembelajaran berlangsung dan mengamati siswa yang menjadi pengamatan nya.

c. Refleksi (see)

Pada tahap refleksi (see) siklus 1 peneliti melakukan diskusi bersama dosen, guru IPA dan observer dimana diskusi yang dilakukan berdasarkan pengamatan observer dan transkrip pembelajaran yang telah dibuat oleh peneliti. Hasil diskusi yang didapatkan yaitu dosen dan guru IPA menyarankan agar pembelajaran pada siklus 2 dilaksananakan dengan membagi siswa dalam berkelompok dan melakukan kerja kelompok. Hal ini bertujuan untuk memperbaiki proses pembelajaran pada siklus 2.

Pada siklus 2 peneliti juga melakukan diskusi sama seperti siklus 1 dimana observer yang mengamati siswa memaparkan temuan nya tentang kegiatan pembelajaran yang dilakukan oleh peneliti sebagai guru model.

Hasil dari transkrip percakapan proses pembelajaran yang telah dibuat disajikan dalam bentuk grafik pada gambar 2 yaitu Grafik transkrip pembelajaran siklus 1 dan gambar 3 Grafik transkrip pembelajaran siklus 2 sebagai berikut: 


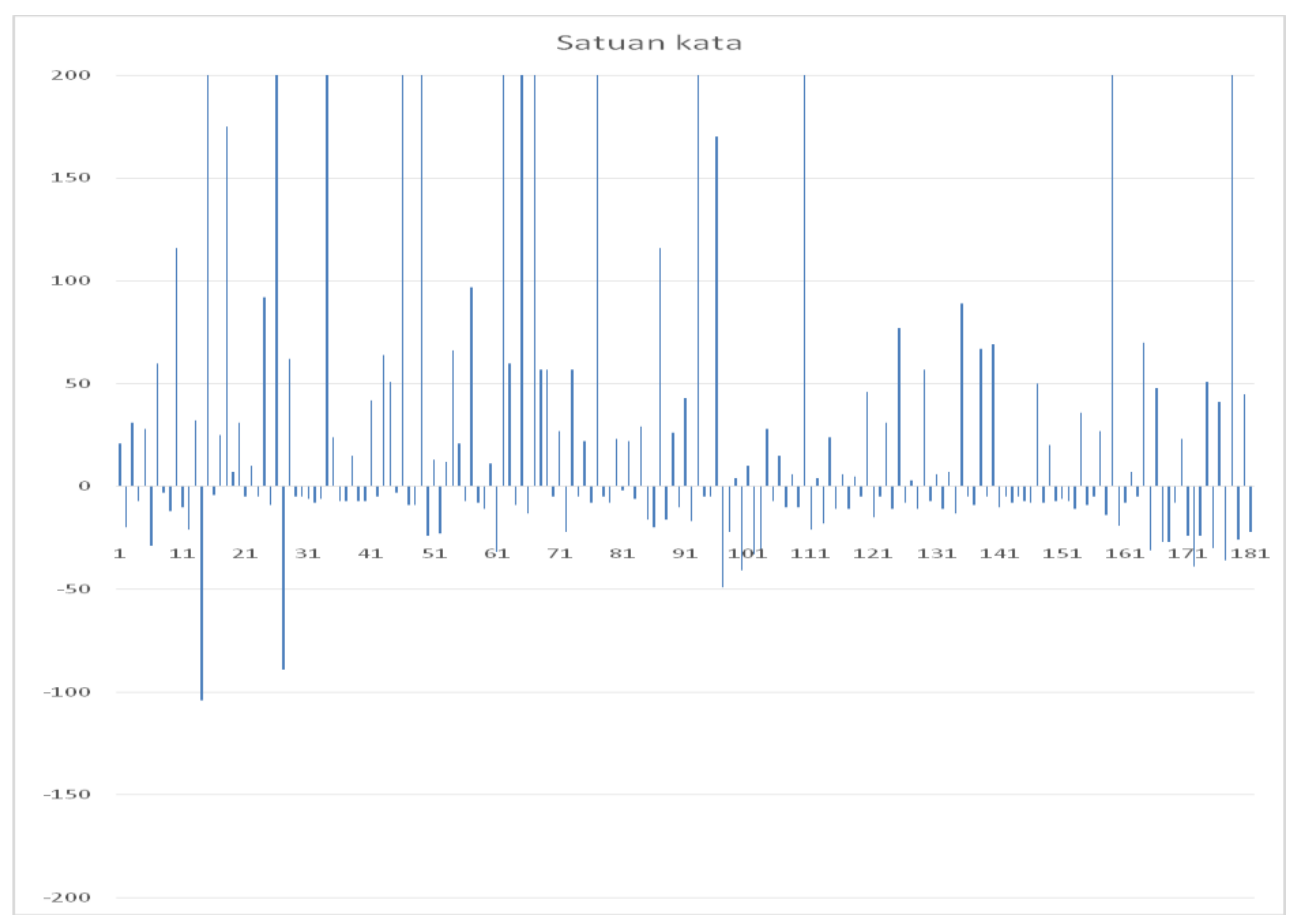

Gambar 2. Grafik transkrip pembelajaran siklus 1

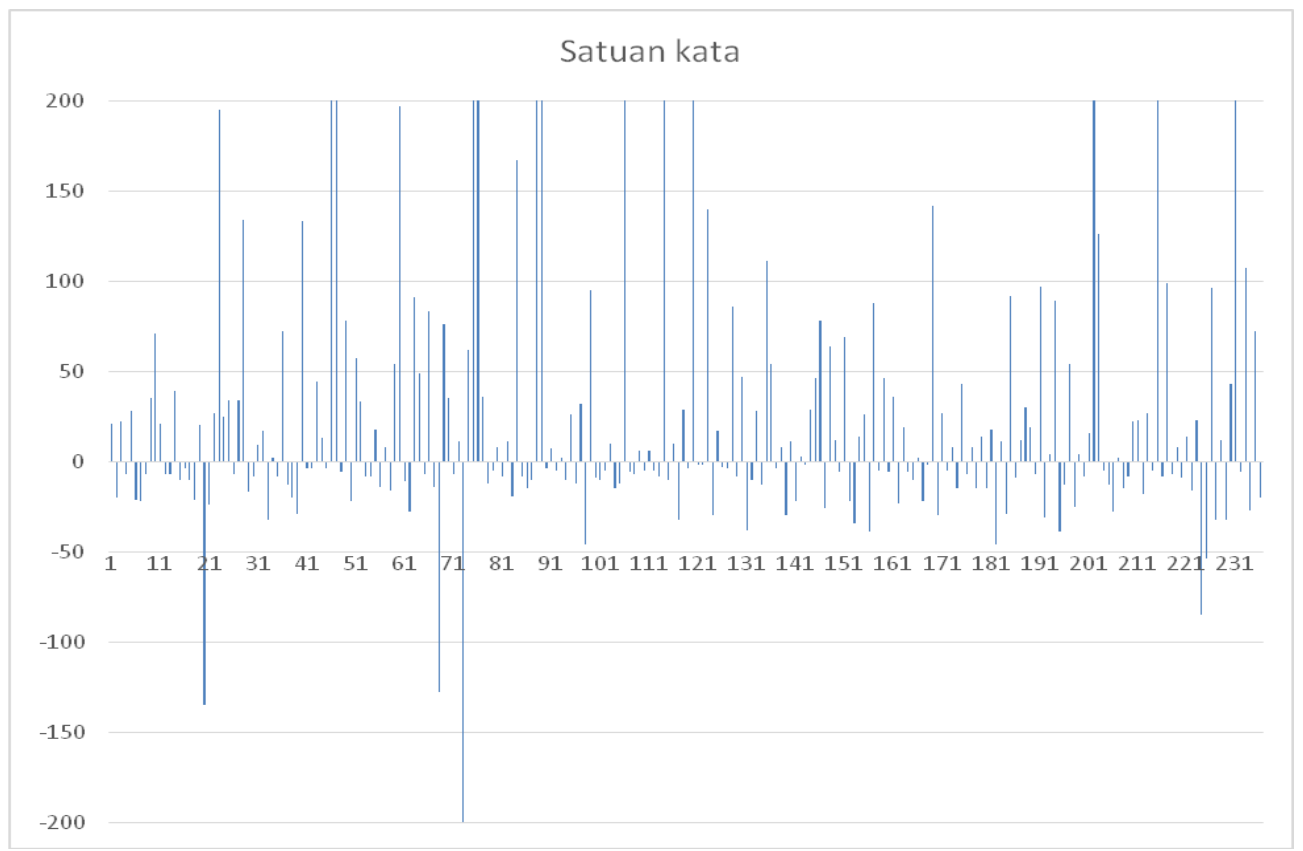

Gambar 3. Grafik transkrip pembelajaran siklus 2

Gambar 2 dan 3 menunjukkan grafik satuan kata transkrip pembelajaran secara keseluruhan dimana bagian atas adalah sesi percakapan yang dilakukan guru dan bagian bawah adalah sesi percakapan yang dilakukan siswa. Sementara garis mendatar yang membatasi sesi percakapan guru dan siswa adalah index percakapan yang terekam pada transkrip secara keseluruhan. Index ini juga merupakan sequens waktu (dalam menit) saat pembelajaran terjadi (Amintarti et al., 2020).

Kegiatan pembelajaran pada siklus 1 telah disiapkan dengan baik, hal ini 
berdasarkan perencanaan (plan) yang telah dilakukan bersama dengan dosen dan guru IPA. Adapun materi yang disampaikan pada saat open class siklus 1 yaitu tentang topik sifat-sifat cahaya. Kelas VIII.2 SMP Islam Al-Falah menurut guru IPA merupakan kelas yang cukup aktif dalam proses pembelajaran. Selama tahap pelaksanaan (do) para siswa tampak mengikuti pembelajaran dengan baik meskipun banyak kendala yang terjadi selama pembelajaran daring ini. Terdapat 3 atau 4 orang siswa yang mengkuti pembelajaran dengan baik serta merespon pertanyaan dari guru model. Dari gambar 2 yaitu grafik satuan kata siklus 1 terlihat bahwa siswa cukup merespon guru dengan baik namun pembelajaran nya masih di dominasi oleh guru atau bersifat teacher centered. Pada saat refleksi dosen dan guru IPA menyarankan untuk membagi siswa dalam beberapa kelompok hal ini bertujuan pada saat proses pembelajaran siswa dapat aktif mengerjakan tugas kelompok yang diberikan guru model sehingga proses pembelajaran dapat bersifat student centered.

Selanjutnya kegiatan siklus 2 dilakukan dengan tujuan untuk memperbaiki proses pembelajaran pada siklus 1. Pada siklus 2 kegiatan pembelajaran yang akan dilakukan juga telah disiapkan dengan baik sebagaimana saran dari dosen dan guru IPA pada refleksi siklus 1. Adapun materi yang disampaikan pada saat open class yaitu tentang pemantulan cahaya pada cermin dimana aplikasi nya sangat banyak dalam kehidupan sehari-hari sehinggan siswa dapat menjadi lingkungan nya sebagai sumber belajar. Selama tahap pelaksanaan siswa tampak mengikuti proses pembelajaran dengan baik. Siswa dibagi menjadi 4 kelompok dengan anggota 1 kelompok sebanyak 8 orang. Pertama-tama guru model menjelaskan sedikit materi dan contoh soal, kemudian guru model memberikan latihan soal yang akan dikerjakan perkelompok. Namun pada saat diskusi kelompok banyak siswa tidak merespon dan mencari jawaban atas latihan soal yang diberikan. Hal ini diduga karena soal yang diberikan terlalu sulit padahal guru model mengambil soal dari contoh soal yang ada di buku yang dipakai siswa. Hal ini terjadi karena kurang nya motivasi atau minat siswa dalam belajar selama pembelajaran daring. Terdapat 4 atau 5 orang siswa yang merespon guru dengan sangat baik. Dari gambar 3 yaitu grafik satuan kata siklus 2 terlihat bahwa siswa merespon guru dengan baik selama pembelajaran berlangsung namun proses pembelajaran nya masih di dominasi oleh guru atau bersifat teacher centered. Pada tahap refleksi guru IPA menyampaikan pendapat nya bahwa proses pembelajaran yang dilakukan sudah berjalan dengan baik. Sementara para observer juga menyampaikan temuan nya tentang proses pembelajaran yang berlangsung.

Berdasarkan analisis transkrip pembelajaran secara keseluruhan pada siklus 1 dan siklus 2 terdapat 5-7 siswa yang benar-benar aktif selama pembelajaran. Sedangkan siswa lainnya tidak aktif sama sekali selama pembelajaran. Hal ini bisa saja terjadi karena kurangnya minat belajar siswa dan motivasi belajar pada setiap siswa yang berbeda-beda karena diawal pembelajaran guru model sudah memberikan semangat kepada siswa dan meminta siswa untuk aktif dalam pembelajaran. Menurut (Yasin, 2015) Faktor yang menyebabkan ketidakatifan siswa dalam proses pembelajaran dapat disebabkan oleh banyak penyebab diantaranya bisa berasal dari diri siswa (faktor internal) seperti gangguan psikologis atau fisik sehingga kurangnya minat belajar siswa sehingga siswa menjadi malas dan ragu untuk menyampaikan pendapatnya. Kemudian faktor eksternal yaitu dari guru seperti kehadiran guru yang tidak diharapkan, dari mata pelajaran, dari model 
pembelajaran yang digunakan, serta dari lingkungan kelas dan sekolah.

Secara keseluruhan dapat disimpulkan bahwa proses pembelajaran IPA pada siklus 1 dan siklus 2 masih di dominasi oleh guru atau bersifat teacher centered. Kesempatan siswa untuk berbicara sudah diberikan oleh guru dengan pertanyaan-pertanyaan yang ada dan diskusi kelompok. Hal ini sejalan dengan penelitian (Amintarti et al., 2020) dimana pembelajaran kimia yang dilakukan masih didominasi guru, kesempatan siswa banyak berbicara dan mengemukakan pendapat terdapat pada sesi presentasi hasil kerja kelompok. Pada pelaksanaan Lesson study di SMP Islam Al-Falah terdapat kendala yang terjadi diantara nya pembelajaran yang dilakukan secara daring sehingga siswa yang berada ditempat yang tidak terdapat jaringan tidak dapat mengikuti pembelajaran. Selain itu waktu pelaksanaan open class yang sangat singkat yaitu 30 menit. Meskipun perencanaan (plan) pada siklus 1 dan 2 telah direncanakan dengan sangat baik namun proses pembelajaran masih di dominasi guru (teacher centered).

\section{KESIMPULAN}

Berdasarkan hasil dan diskusi dapat disimpulkan bahwa proses pembelajaran IPA dengan lesson study pada materi cahaya sudah terlaksana dengan baik sesuai dengan tahapan lesson study yaitu perencanaan (plan), pelaksanaan (do) dan refleksi (see). Pelaksanaan siklus 1 telah dilaksanakan dan dilakukan refleksi dengan tujuan untuk memperbaiki proses pembelajaran pada siklus 2. Berdasarkan hasil transkrip pembelajaran (TBLA) siklus 1 dan siklus 2 yang kemudian dibuat dalam bentuk grafik satuan kata terlihat bahwa proses pembelajaran masih di dominasi oleh guru atau bersifat teacher centered. Adapun kendala yang didapatkan yaitu pembelajaran yang dilakukan secara daring sehingga siswa yang berada di tempat yang tidak terdapat jaringan tidak dapat mengikuti pembelajaran. Selain itu waktu pelaksanaan open class yang sangat singkat yaitu 30 menit. Bagi peneliti analisis pembelajaran melalui lesson study berbasis TBLA (Transcript Based Lesson Analysis) sangat baik dilakukan karena percakapan yang terjadi antara guru dan siswa dapat dibuat dengan sedetail mungkin yang kemudian di analisis. Bagi guru penelitian ini sangat baik untuk memperbaiki pembelajaran selanjutnya.

\section{REFERENSI}

Amintarti, S., Winarti, A., Sholahuddin, A., Syahmani, S., \& Wati, M. (2020). Penerapan Transcript Based Lesson Analysis (TBLA) Sebagai Upaya Peningkatan Pembelajaran Kimia. Quantum: Jurnal Inovasi Pendidikan Sains, 11(2):149.

Creswell, J. W. (2017). Research Design Pendekatan Kualitatif, Kuantitatif, dan Mixed. Yogyakarta: Pustaka Pelajar.

Dewi, A. A. (2018). Guru mata tombak pendidikan. Jawa Barat: CV Jejak (Jejak Publisher).

Ernawati, E., \& Effendi, E. (2017). Penerapan Lesson Study pada Pembelajaran Fisika Materi Perubahan Wujud Zat. JIPFRI (Jurnal Inovasi Pendidikan Fisika dan Riset Ilmiah), 1(2):41-46.

Kusdiastuti, M., Harjono, A., Gunawan, G., \& Nisyah, M. (2019). Respon Guru dan Peserta Didik Terhadap Pembelajaran Fisika dengan Model Inkuiri Terbimbing Dipadu Advance Organizer. Jurnal Pendidikan Fisika dan Teknologi, 5(1):150-155.

Maison, Asrial, \& Syaiful M. (2015). Peningkatan Aktivitas Belajar Siswa pada Materi Fisika Melalui Kegiatan Lesson Study di SMP 17 
Kota Jambi. Jurnal Pengabdian pada Masyarakat, 30 (4):55-60.

Rahayu, D. S., Rahmawan, S., Hendayana, S., Muslim, M., \& Sendi, S. (2020). Pattern of Analysis Students' Knowledge Construction Using Transcript-Based Lesson Analysis. Proceedings of the 4th Asian Education Symposium (AES 2019), 438:140-144.

Sari, A.N., Elvina, O. \& Dimas, A. (2019). Kemampuan Representasi Siswa SMP pada Materi Pesawat Sederhana. Prosiding SNFA (Seminar Nasional Fisika dan Aplikasinya).

Sarkar Arani, M. R. (2017). Raising the quality of teaching through Kyouzai Kenkyuu - the study of teaching materials. International Journal for Lesson and Learning Studies, 6(1):10-26.

Setyosari, P. (2020). Desain Pembelajaran. Jakarta Timur: Bumi Aksara.

Suminem, S. (2016). Meningkatkan Hasil Belajar Fisika Dalam Materi Gerak Melingkar Melalui Implementasi Lesson Study Menggunakan Model Keterampilan Proses Sains Siswa Man 2 Pontianak. Jurnal Pendidikan Matematika dan IPA, 4(2):42-48.

Susanti, N. Desmalwan \& Basuki F.R. (2016). Implementation Wave Kit as Efforts to Increase Student Learning Skills. Proceeding The 2nd International Conference On Teacher Training and Education Sebelas Maret University, 2 (1):448-456.

Yasin, A. (2015). Pengaruh Pembelajaran Group
Investigation Terhadap Tingkat

Keaktifan Siswa dalam

Pembelajaran Sejarah

Kebudayaan Islam. Online

Thesis, 10(2). 